\title{
Predicted Postoperative Product and Diffusion Heterogeneity Index in the Evaluation of Candidates for Lung Resection
}

\author{
Jeng-Shing Wang MD MSc, Raja T Abboud MD, and Brian L Graham PhD
}

\begin{abstract}
OBJECTIVES: The primary objective of this retrospective study was to evaluate whether abnormal predicted postoperative variables and predicted postoperative product are useful in predicting postoperative complications. The secondary objective was to assess whether an abnormal diffusion heterogeneity index is associated with increased postoperative complications. METHODS: In this retrospective study we evaluated the medical records of 57 patients who underwent lung resection for lung cancer. Calculations of the predicted postoperative variables were done using preoperative testing data, including the extent of the resected lung segments. Predicted postoperative product was obtained by multiplying the predicted postoperative percent-of-predicted $F E V_{1}$ by the predicted postoperative percent-of-predicted single-breath diffusing capacity of the lung for carbon monoxide $\left(\mathrm{D}_{\mathrm{LCO}}\right)$. The measured product was obtained by multiplying $\mathrm{FEV}_{1}$ by $\mathrm{D}_{\mathrm{LCO}}$. We derived diffusion heterogeneity index from measurements of the single-breath $\mathrm{D}_{\mathrm{LCO}}$ with the 3-equation method, as a measure of the heterogeneity of the distribution of gas exchange in the lung. RESULTS: Patients with complications had lower predicted postoperative $\operatorname{FEV}_{1}(P<.001)$, lower predicted postoperative $\mathrm{D}_{\mathrm{LCO}}(P<.001)$, lower predicted postoperative maximal oxygen uptake $(P<.001)$, lower predicted postoperative increase in percent-of-predicted $\mathrm{D}_{\mathrm{LCO}}$ at $70 \%$ work load from at-rest percent-of-predicted $\mathrm{D}_{\mathrm{LCO}}\left(\Delta \mathrm{D}_{\mathrm{LCO}} \%\right)(P<.001)$, lower predicted postoperative product $(P<.001)$, and lower measured product $(P=.004)$. Interestingly, diffusion heterogeneity index increased with exercise in all patients with complications but decreased with exercise in all patients without complications. CONCLUSIONS: The predicted postoperative variables, predicted postoperative product, measured product, and diffusion heterogeneity index are potentially useful predictors of complications in candidates for lung resection. Key words: diffusing capacity; exercise testing; lung resection; predicted postoperative product; preoperative evaluation; spirometry. [Respir Care 2011;56(4):449-455. (C) 2011 Daedalus Enterprises]
\end{abstract}

\footnotetext{
Jeng-Shing Wang MD MSc is affiliated with the Division of Respirology, Antai Medical Care Cooperation, Antai Tian-Sheng Memorial Hospital, Pingtung, Taiwan. Raja T Abboud MD is affiliated with the Division of Respiratory Medicine, University of British Columbia, and with Seymour Health Centre, Vancouver, British Columbia, Canada. Brian L Graham PhD is affiliated with the Division of Respirology, Critical Care, and Sleep Medicine, University of Saskatchewan, Saskatoon, Saskatchewan, Canada.
}

This research was partly supported by a grant from the British Columbia Medical Services Foundation, which provided the analyzer and computer for the 3-equation $\mathrm{D}_{\mathrm{LCO}}$; and by the Tuberculosis and Chest Disabled Veterans Association, which funded the purchase of the exercise equipment. Dr Wang was partly supported by a fellowship from the
British Columbia Lung Association, and by the Vancouver General Hospital Foundation. This study was performed as part of Dr Wang's master's thesis in experimental medicine, University of British Columbia, Vancouver, British Columbia, Canada.

The authors have disclosed no conflicts of interest.

Correspondence: Jeng-Shing Wang MD MSc, Division of Respirology, Antai Medical Care Cooperation, Antai Tian-Sheng Memorial Hospital, No. 166 Min-Shiang Street, Kaohsiung 800, Taiwan. E-mail: wangjs6@hotmail.com.

DOI: $10.4187 /$ respcare. 00850 


\section{Predicted Postoperative Product and Diffusion Heterogeneity Index}

\section{Introduction}

Lung-function testing, including $\mathrm{FEV}_{1}$ and single-breath diffusing capacity of the lung for carbon monoxide $\left(\mathrm{D}_{\mathrm{LCO}}\right)$, has been used in assessing patients with non-small-cell lung cancer. ${ }^{1,2}$ Some studies have suggested that $\mathrm{D}_{\mathrm{LCO}}$ should be assessed routinely in candidates for major pulmonary surgery, regardless of spirometry findings. ${ }^{3,4}$ More recently, the predicted postoperative $\mathrm{FEV}_{1}$ and predicted postoperative $\mathrm{D}_{\mathrm{LCO}}$, estimated via preoperative lung-perfusion scanning and assessment of the contribution of the resected lung to overall function, ${ }^{5}$ were shown to have predictive value for postoperative complications following lung resection. The product of predicted postoperative percent-of-predicted $\mathrm{FEV}_{1}$ and predicted postoperative percent-of-predicted $\mathrm{D}_{\mathrm{LCO}}$ (the so-called predicted postoperative product), may be a useful value that combines the important elements of both measurements. ${ }^{6}$

The effects of diffusion heterogeneity on $\mathrm{D}_{\mathrm{LCO}}$ measurements was recently described. ${ }^{7}$ Graham et al developed an index to quantify diffusion heterogeneity (the diffusion heterogeneity index). ${ }^{8}$ The overall 3 -equation $\mathrm{D}_{\mathrm{LCO}}$ uses all of the information measured during inhalation, breath-holding, and exhalation to calculate the average diffusing capacity of the entire lung. The alveolar gas sample consists of all of the gas exhaled following deadspace washout. This large sample of alveolar gas is then divided into 4 equal-volume samples and the data are reanalyzed 4 times, with a separate 3 -equation $\mathrm{D}_{\mathrm{LCO}}$ calculated for each of the 4 smaller samples. The diffusion heterogeneity index is a measure of how much the $\mathrm{D}_{\mathrm{LCO}}$ measured in the 4 small samples differs from the $\mathrm{D}_{\mathrm{LCO}}$ measured in the large sample. In a perfectly homogeneous lung, the diffusion heterogeneity index would be zero. In a normal, healthy subject the diffusion heterogeneity index is typically near zero. ${ }^{8}$ Smokers with normal $\mathrm{D}_{\mathrm{LCO}}$ and normal $\mathrm{FEV}_{1}$ have an elevated diffusion heterogeneity index.

The primary objective of this retrospective study was to evaluate whether abnormal predicted postoperative variables and predicted postoperative product are useful in predicting morbidity and mortality following lung resection. The secondary objective was to determine whether abnormal diffusion heterogeneity index is associated with increased postoperative complications following lung resection.

\section{Methods}

This study was approved by the University of British Columbia Clinical Screening Committee for Research and Other Studies Involving Human Patients. All patients gave informed consent before participating. The experimental protocol was the same as in our previous study. ${ }^{9}$

\section{Subjects}

Retrospectively, we evaluated all patients with a diagnosis of non-small-cell lung cancer who underwent thoracotomy for lung resection at Vancouver General Hospital, during an 8-month period. The preoperative data were recorded, and the postoperative course of the patients was followed carefully with detailed assessment. We evaluated $\mathrm{D}_{\mathrm{LCO}}$ during exercise before lung resection with the 3-equation $\mathrm{D}_{\mathrm{LCO}}$ method. Since the 3-equation method can determine $\mathrm{D}_{\mathrm{LCO}}$ accurately without the need for breath-holding in the single-breath maneuver, this method is useful in evaluating $\mathrm{D}_{\mathrm{LCO}}$ during moderate to high intensity exercise, in which prolonged breath-holding is difficult. ${ }^{9} \mathrm{We}$ related changes in $\mathrm{D}_{\mathrm{LCO}}$ during exercise to postoperative complications.

\section{Predicted Postoperative Value}

The calculation of the predicted postoperative value variable was described in previous studies ${ }^{10,11}$ :

Predicted postoperative value $=$ preoperative value $\times[1-(\mathrm{S}-\mathrm{N}) /(19-\mathrm{N})]$

where $S$ is the number of resected segments (10 in the right lung, and 9 in the left lung), and $\mathrm{N}$ is the number of nonfunctional or obstructed segments in the resected lung, determined from the preoperative chest radiograph, chest computed tomogram, and bronchoscopy. For more than $75 \%$ obstruction of a segment, $\mathrm{N}$ is taken as 1 ; for obstruction of $50-75 \%, \mathrm{~N}$ is taken as 0.5 ; and milder obstruction is ignored. ${ }^{12}$ The predicted postoperative product is the product of predicted postoperative percent-of-predicted $\mathrm{FEV}_{1}$ and predicted postoperative percent-of-predicted $\mathrm{D}_{\mathrm{LCO}}$. We defined the measured product as the product of measured preoperative percent-of-predicted $\mathrm{FEV}_{1}$ and measured preoperative percent-of-predicted $\mathrm{D}_{\mathrm{LCO}} \cdot{ }^{10}$

\section{Diffusion Heterogeneity Index}

The diffusion heterogeneity index reflects the degree to which $\mathrm{D}_{\mathrm{LCO}}$ values calculated from 4 equal-volume alveolar gas samples deviate from the $\mathrm{D}_{\mathrm{LCO}}$ from the entire alveolar gas sample, by measuring the root-mean-square difference ${ }^{8}$ of the normalized $\mathrm{D}_{\text {LCO }}$ values (Fig. 1). Since lung regions that are better ventilated empty earlier in exhalation, $\mathrm{D}_{\mathrm{LCO}}$ from 4 separate samples show $\mathrm{D}_{\mathrm{LCO}}$ differences. The 3-equation method is needed because it can analytically compensate for the size and timing of the alveolar sample and does not introduce errors in $\mathrm{D}_{\mathrm{LCO}}$ when sample collection is delayed. ${ }^{8}$ For a perfectly homogeneous lung, the diffusion heterogeneity index is zero. 


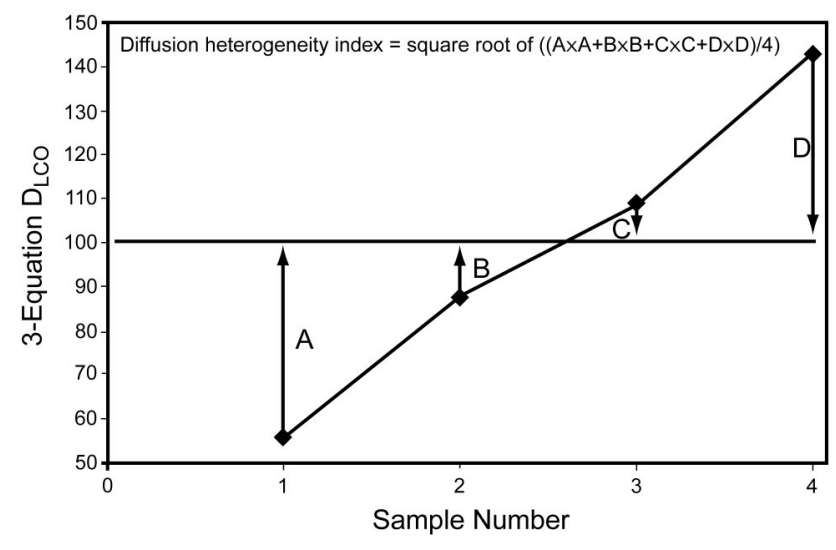

Fig. 1. Normalized 3-equation values for the diffusing capacity of the lung for carbon monoxide $\left(D_{\mathrm{LCO}}\right)$, calculated from 4 equal alveolar gas samples by expressing them as a percentage of $D_{L C O}$ calculated from the total alveolar gas sample. Points A, B, C, and $D$ denote the difference between the 4 normalized values calculated from the 4 equal alveolar gas samples, respectively, and the normalized $D_{\text {LCO }}$ from the total alveolar gas sample (indicated by the horizontal line). The root mean square difference of the 4 samples is the diffusion heterogeneity index.

The diffusion heterogeneity index increases as the heterogeneity of diffusion in the lung increases.

\section{Postoperative Complications}

Two thoracic surgeons did all the thoracotomies and pulmonary resections. The patients' postoperative courses were followed carefully, with detailed assessment and recording of complications. We classified postoperative inhospital complications into mortality, cardiovascular, and pulmonary morbidity. ${ }^{10}$

\section{Statistical Analyses}

We analyzed the data with statistics software (Excel 2007, Microsoft, Redmond, Washington, and SPSS 17.0, SPSS, Chicago, Illinois). We determined the means and standard deviations for the whole group and for patients with and without complications. We compared continuous variables with the 2-tailed Student $t$ test, and categorical variables with the chi-square test. We analyzed multiple variables with stepwise logistic regression, ${ }^{13}$ to investigate the relative usefulness of the combination of different variables for predicting postoperative complications. Differences between groups were considered significant if $P<.05$. We calculated the receiver operating characteristic curves of these variables for overall complications, and the area under the receiver operating characteristic curve. ${ }^{14}$ We used the receiver operating characteristic curve to define the best cut points for the variables in relation to postoperative complications. Further validation of our cut points should be performed prior to clinical use. ${ }^{15,16}$ Sensitivity and specificity for each variable were determined. ${ }^{14}$ We compared the area under the receiver operating characteristic curves with the method of Hanley and McNeil. ${ }^{17}$

\section{Results}

The 57 patients had a mean age of $64 \pm 10 \mathrm{y} ; 39(68 \%)$ were men, and 18 (32\%) were women. Mean height was $170 \pm 10 \mathrm{~cm}$, and mean weight was $74 \pm 15 \mathrm{~kg}$. Twentyfour patients $(42 \%)$ were smokers, and their mean smoking history was $55 \pm 30$ pack-years. Twenty-two (39\%) were ex-smokers, and their mean smoking history was $34 \pm 24$ pack-years. Eleven patients (19\%) had never smoked. Twenty-four patients $(41 \%)$ had a diagnosis of COPD. The surgeries were 10 pneumonectomies, 2 bilobectomies, 32 lobectomies, 6 segmentectomies, 4 wedge resections, and 3 thoracotomies without lung resection.

Table 1 shows the preoperative lung-function data. The predicted postoperative percent-of-predicted $\mathrm{FEV}_{1}$ was $66 \pm 22 \%$. Thirty-three patients had mild or moderate ventilatory obstruction. The predicted postoperative percent-of-predicted $\mathrm{D}_{\mathrm{LCO}}$ was $60 \pm 19 \%$. Thirty patients had mild or moderate $\mathrm{D}_{\mathrm{LCO}}$ impairment. Maximal exercise capacity was reduced in 36 patients. The predicted postoperative maximum oxygen uptake was $15 \pm 4 \mathrm{~mL} / \mathrm{kg} / \mathrm{min}$. To adjust for differences in sex, age, and height in different patients, we express $\mathrm{D}_{\mathrm{LCO}}$ values (at rest and exercise) as percent-of-predicted at-rest $\mathrm{D}_{\mathrm{LCO}}$. We measured the change in $\mathrm{D}_{\mathrm{LCO}}$ at $70 \%$ work load above at-rest $\mathrm{D}_{\mathrm{LCO}}$ $\left(\Delta \mathrm{D}_{\mathrm{LCO}}\right)$. The predicted postoperative $\Delta \mathrm{D}_{\mathrm{LCO}}$ was $20 \pm 16 \%$, and there was significant inter-patient variability in $\Delta \mathrm{D}_{\mathrm{LCO}}$.

Postoperative complications occurred in 19 patients (33\%), and included mortality in 2 (4\%) (both from pulmonary edema), cardiovascular morbidity in 12 (21\%), and pulmonary morbidity in 13 (23\%). Arrhythmia (atrial fibrillation in 10 patients, and ventricular premature contraction in 1 patient) was the major cardiovascular morbidity, occurring in $19 \%$ of all the patients. Two patients had pulmonary edema and one had shock. Pneumonia was the major pulmonary morbidity, occurring in 7 patients (12\% of all the patients). Five patients had atelectasis, 4 developed respiratory insufficiency, and 2 required ventilatory support and re-intubation.

The patients with complications were older than those without complications (70 y vs $61 \mathrm{y}, P=.005$ ); were more frequently diagnosed with COPD (14/19 vs 10/38, $P=.003$ ); had more pack-years of smoking (60 vs 50, $P=.01)$. Table 2 lists preoperative lung-function variables in relation to complications. Interestingly, patients with complications had higher diffusion heterogeneity index $(P=.02)$, higher diffusion heterogeneity index during exercise $(P<.001)$, and higher change in diffusion het- 
Table 1. Preoperative Lung-Function Data

\begin{tabular}{|c|c|c|}
\hline & Mean \pm SD (range) & $\begin{array}{c}\text { Mean } \pm \text { SD } \\
\% \text { Predicted (range) }\end{array}$ \\
\hline \multicolumn{3}{|l|}{ Predicted Postoperative Value } \\
\hline $\mathrm{FEV}_{1}(\mathrm{~L})$ & $1.97 \pm 0.70(0.77-3.50)$ & $66 \pm 22(30-116)$ \\
\hline $\mathrm{D}_{\mathrm{LCO}}(\mathrm{mL} / \mathrm{min} / \mathrm{mm} \mathrm{Hg})$ & $15.12 \pm 5.63(6.21-31.02)$ & $60 \pm 19(24-95)$ \\
\hline Maximal oxygen uptake (mL/kg/min) & $15 \pm 4(9-25)$ & $62 \pm 13(36-98)$ \\
\hline$\Delta \mathrm{D}_{\mathrm{LCO}} \% *$ & $20 \pm 16(-8$ to 61$)$ & NA \\
\hline Predicted postoperative product & $4,104 \pm 2,201(898-9,200)$ & NA \\
\hline Measured product & $5,438 \pm 3,341(1,722-11,528)$ & NA \\
\hline Index of diffusion heterogeneity (\%) & $42 \pm 20(15-106)$ & NA \\
\hline Index of diffusion heterogeneity during exercise $(\%) \dagger$ & $43 \pm 22(15-109)$ & NA \\
\hline$\Delta$ Index of diffusion heterogeneity $(\%) \neq$ & $-1 \pm 18(-40$ to 60$)$ & NA \\
\hline \multicolumn{3}{|c|}{$\begin{array}{l}\text { * Percent-of-predicted for the } 3 \text {-equation method of calculating at-rest single-breath diffusing capacity of the lung for carbon monoxide }\left(\mathrm{D}_{\mathrm{LCO}}\right) \text {. } \\
\dagger \text { Index of diffusion heterogeneity at } 70 \% \text { of maximal workload. } \\
¥ \text { Mean difference in index of diffusion heterogeneity during exercise from at-rest index of diffusion heterogeneity. } \\
\Delta \mathrm{D}_{\mathrm{LCO}} \%=\text { change in percent-of-predicted } \mathrm{D}_{\mathrm{LCO}} \text { at } 70 \% \text { workload from at-rest } \mathrm{D}_{\mathrm{LCO}} \\
\mathrm{NA}=\text { not applicable }\end{array}$} \\
\hline
\end{tabular}

Table 2. Preoperative Lung-Function Variables in Relation to Complications

\begin{tabular}{|c|c|c|c|}
\hline & $\begin{array}{l}\text { Complications } \\
(\text { mean } \pm \mathrm{SD}) \\
(n=19)\end{array}$ & $\begin{array}{l}\text { No Complications } \\
(\text { mean } \pm \mathrm{SD}) \\
(n=38)\end{array}$ & $P$ \\
\hline \multicolumn{4}{|l|}{ Predicted Postoperative Value } \\
\hline $\mathrm{FEV}_{1} \%$ predicted & $52 \pm 13$ & $73 \pm 23$ & $<.001$ \\
\hline $\mathrm{D}_{\mathrm{LCO}} \%$ predicted & $45 \pm 13$ & $69 \pm 16$ & $<.001$ \\
\hline Maximal oxygen uptake (mL/kg/min) & $12 \pm 2$ & $16 \pm 4$ & $<.001$ \\
\hline$\Delta \mathrm{D}_{\mathrm{LCO}} \% *$ & $5 \pm 8$ & $28 \pm 12$ & $<.001$ \\
\hline Predicted postoperative product & $2,543 \pm 1,224$ & $5,057 \pm 2,704$ & $<.001$ \\
\hline Measured product & $4,588 \pm 1,343$ & $7,732 \pm 1,528$ & .004 \\
\hline Index of diffusion heterogeneity (\%) & $51 \pm 25$ & $38 \pm 15$ & .02 \\
\hline Index of diffusion heterogeneity during exercise $(\%) \dagger$ & $63 \pm 26$ & $33 \pm 9$ & $<.001$ \\
\hline$\Delta$ Index of diffusion heterogeneity $(\%) \neq$ & $12 \pm 19$ & $-6 \pm 12$ & .006 \\
\hline $\begin{array}{l}\text { * Percent-of-predicted for the 3-equation method of calculating at-rest si } \\
\dagger \text { Index of diffusion heterogeneity at } 70 \% \text { of maximal workload. } \\
\ddagger \text { Mean difference in index of diffusion heterogeneity during exercise fro } \\
\Delta \mathrm{D}_{\mathrm{LCO}} \% \text { predicted = change in percent-of-predicted } \mathrm{D}_{\mathrm{LCO}} \text { at } 70 \% \text { work }\end{array}$ & $\begin{array}{l}\text { apacity of the lung for } \\
\text { usion heterogeneity. }\end{array}$ & co). & \\
\hline
\end{tabular}

erogeneity index $(P=.006)$ (see Table 2$)$. Moreover, the diffusion heterogeneity index during exercise was larger than the at-rest diffusion heterogeneity index in the patients with complications, but the diffusion heterogeneity index during exercise was smaller than the at-rest diffusion heterogeneity index in the patients without complications. The diffusion heterogeneity index increased with exercise in the patients with complications, but it decreased with exercise in the patients without complications.

Table 3 shows the $\beta$ coefficient and intercept values for the preoperative variables; it appears that all 9 predictors, as indicated by significant $P$ values, are potentially useful for overall complications prediction. Multiple-variable analyses via backward stepwise logistic regressions showed that predicted postoperative $\Delta \mathrm{D}_{\mathrm{LCO}} \%$ remained at the end of the run after the models combining all 9 different variables.

The largest area under the receiver operating characteristic curve was calculated from predicted postoperative $\Delta \mathrm{D}_{\mathrm{LCO}} \%$ for overall complications (Fig. 2), and the difference was statistically significant from that of the other variables. Table 4 compares the postoperative complications with cut points for the preoperative variables.

When the change in diffusion heterogeneity index was analyzed as a categorical variable, such that an increase in diffusion heterogeneity index with exercise was classified as a negative result and a decrease in diffusion heterogeneity index with exercise was classified as a positive result, then the sensitivity and specificity were both $100 \%$, since all patients with postoperative complications had a 
Table 3. $\quad \beta$ Coefficient and Intercept Values From the Regression Equations for the Preoperative Variables' Prediction of Postoperative Complications*

\begin{tabular}{lrrc}
\hline \hline & $\beta$ Coefficient & Intercept & \multicolumn{1}{c}{$P$} \\
\hline Predicted postoperative value & & & \\
$\mathrm{FEV}_{1} \%$ predicted & -0.001 & 5.464 & .008 \\
$\mathrm{D}_{\mathrm{LCO}} \%$ predicted & -0.566 & 7.158 & .007 \\
Maximal oxygen uptake & 0.125 & -6.075 & .009 \\
$\Delta \mathrm{D}_{\mathrm{LCO}} \%$ & 0.102 & -0.934 & $<.001$ \\
Predicted postoperative product & -0.321 & 4.041 & .001 \\
Measured product & 0.035 & -2.183 & .03 \\
Index of diffusion heterogeneity & -0.056 & 2.761 & .04 \\
Index of diffusion heterogeneity & -0.1 & 5.145 & .002 \\
$\quad$ during exercise $\dagger$ & & & \\
$\Delta$ Index of diffusion heterogeneity & -0.001 & 2.365 & .005
\end{tabular}

* This is a logistic regression model that calculates the log odds of disease, which can be used to calculate the probability of outcome.

Index of diffusion heterogeneity at $70 \%$ of maximal workload.

$¥$ Mean difference in index of diffusion heterogeneity during exercise from at-rest index of diffusion heterogeneity.

$\Delta \mathrm{D}_{\mathrm{LCO}} \%=$ change in percent-of-predicted diffusing capacity of the lung for carbon monoxide $\left(\mathrm{D}_{\mathrm{LCO}}\right)$ at $70 \%$ workload from at-rest $\mathrm{D}_{\mathrm{LCO}}$

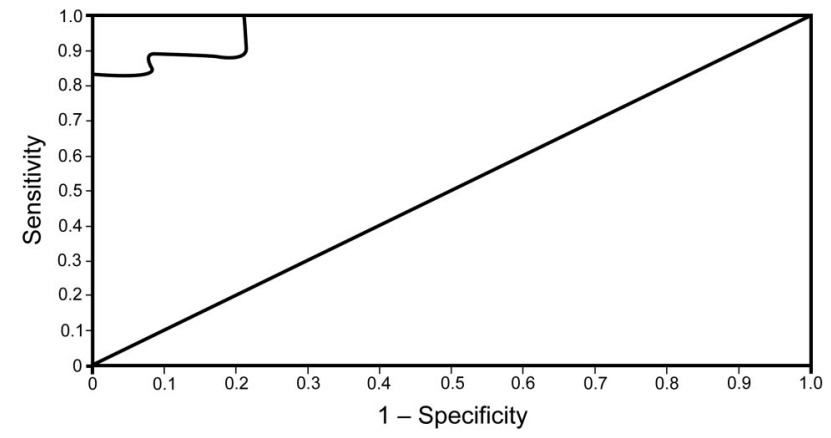

Fig. 2. Receiver operating characteristic curve of preoperative variables for prediction of overall complications. The straight line is the line of identity for a test without any discrimination. The area under the receiver operating characteristic curve of predicted postoperative $\left(70 \%\right.$ work load) $D_{\mathrm{Lco}} \%$ was 0.97 . The best cut point was $14 \%$, at which sensitivity was $89 \%$ and specificity was $92 \%$.

positive preoperative tests, and all patients without complications had a negative preoperative test.

\section{Discussion}

We have evaluated the role of some new indices (predicted postoperative values, predicted postoperative product, measured product, and diffusion heterogeneity index) in the preoperative evaluation of candidates for lung resection. The main finding of our previous study was that patients with complications had only a limited increase in $\mathrm{D}_{\mathrm{LCO}}$ during exercise, expressed as percent-of-predicted at-rest $\mathrm{D}_{\mathrm{LCO}}$, compared to patients without complications.
The present results show that all these new indices are potentially useful in predicting complications (see Tables 2 , 3 , and 4) and that the best cut point for predicting complications was $14 \%$ in predicted postoperative $\Delta D_{\mathrm{LCO}} \%$ (see Table 4 and Fig. 2).

In this study the postoperative complication rate was $33 \%$ and the mortality rate was $4 \%$. Those findings are similar to recent reports, ${ }^{18}$ and the mortality rate of $5 \%$ in our review of 151 pneumonectomy patients, ${ }^{1}$ and are considered acceptable. Cardiac arrhythmia was the major cause of morbidity. But pulmonary edema was the major cause of mortality in this study, suggesting having a similar finding in our retrospective review. ${ }^{1}$ Pulmonary edema and cardiac dysrhythmias may be induced by the supraphysiological stresses imposed on the heart and lung during surgery and postoperatively, due to hyperperfusion of the remaining pulmonary vascular bed.

Studies with quantitative radionuclide lung scanning ${ }^{19,20}$ are useful in preoperative evaluation. Pierce et $\mathrm{al}^{6}$ found that a new index, designated the predicted postoperative product, obtained by multiplying the percent-of-predicted postoperative $\mathrm{FEV}_{1}$ by the percent-of-predicted postoperative $\mathrm{D}_{\mathrm{LCO}}$, has the strongest ability for predicting mortality. The predicted postoperative product is a new concept that includes values of ventilatory function $\left(\mathrm{FEV}_{1}\right)$, gas transfer $\left(\mathrm{D}_{\mathrm{LCO}}\right)$, lung perfusion (lung scan), and the resected lung into a single index. Because the predicted postoperative product uses percent-of-predicted rather than absolute $\mathrm{FEV}_{1}$ and $\mathrm{D}_{\mathrm{LCO}}$ values, it can apply to patients of either sex across a wide range of age and height. The predicted postoperative product allows a patient with a value below the threshold for one criterion based on predicted postoperative $\mathrm{FEV}_{1}$ or predicted postoperative $\mathrm{D}_{\mathrm{LCO}}$ to be accepted for surgery on the basis of a good value in the other. Only a few of our patients had quantitative radionuclide lung scans, but we calculated the predicted postoperative values for $\mathrm{FEV}_{1}$ and $\mathrm{D}_{\mathrm{LCO}}$ from the surgical excision of functional lung segments, using the modified formula of Nakahara et al. ${ }^{11}$ Predicted postoperative FEV determined in that manner was used in a recent study. ${ }^{21}$ We also used this formula to calculate predicted postoperative $\mathrm{D}_{\mathrm{LCO}}$, predicted postoperative oxygen uptake, and predicted postoperative $\Delta \mathrm{D}_{\mathrm{LCO}}$. The predicted postoperative values for $\mathrm{FEV}_{1}$ and $\mathrm{D}_{\mathrm{LCO}}$ enabled us to calculate the predicted postoperative product from the preoperative data in all patients. In this study the calculated predicted postoperative product was useful in predicting postoperative complications. All predicted postoperative variables were also useful predictors for postoperative complications. Recently, a study also showed that predicted postoperative product, predicted postoperative $\mathrm{D}_{\mathrm{LCO}}$, and American Society of Anesthesiology (ASA) score are independent predictors of a need for postoperative ICU admission. ${ }^{22}$ 
Table 4. Comparison of Postoperative Complications Using Cut Points of Preoperative Variables

\begin{tabular}{|c|c|c|c|c|c|}
\hline & $\begin{array}{l}\text { Area Under the Receiver } \\
\text { Operating Characteristic Curve } \\
(95 \% \text { CI })\end{array}$ & $\begin{array}{c}\text { Best Cut } \\
\text { Point }\end{array}$ & $\begin{array}{c}\text { Sensitivity } \\
(\%)\end{array}$ & $\begin{array}{c}\text { Specificity } \\
(\%)\end{array}$ & $P$ \\
\hline \multicolumn{6}{|l|}{ Predicted Postoperative Value } \\
\hline $\mathrm{FEV}_{1} \%$ predicted & $0.78(0.66$ to 0.90$)$ & 60 & 74 & 68 & .06 \\
\hline $\mathrm{D}_{\mathrm{LCO}} \%$ predicted & $0.87(0.77$ to 0.97$)$ & 60 & 88 & 82 & .004 \\
\hline Maximal oxygen uptake & $0.81(0.70$ to 0.93$)$ & 14 & 79 & 66 & .08 \\
\hline$\Delta \mathrm{D}_{\mathrm{LCO}} \% *$ & $0.97(0.94$ to 1.00$)$ & 14 & 89 & 92 & $<.001$ \\
\hline Predicted postoperative product & $0.83(0.72$ to 0.95$)$ & 4,000 & 88 & 74 & .07 \\
\hline Measured product & $0.90(0.81$ to 0.99$)$ & 6,000 & 82 & 77 & .002 \\
\hline Index of diffusion heterogeneity (\%) & $0.68(0.53$ to 0.83$)$ & 40 & 58 & 68 & .05 \\
\hline Index of diffusion heterogeneity exercise $(\%) \dagger$ & $0.88(0.78$ to 0.98$)$ & 40 & 78 & 79 & .003 \\
\hline$\Delta$ Index of diffusion heterogeneity $(\%)$ & $0.80(0.66$ to 0.94$)$ & 0 & 78 & 76 & .005 \\
\hline
\end{tabular}

$\mathrm{D}_{\mathrm{LCO}}$ and exercise are good predictors of postoperative complications. The predicted postoperative $\Delta \mathrm{D}_{\mathrm{LCO}} \%$ can reflect $\mathrm{D}_{\mathrm{LCO}}$ and its response to exercise testing, suggesting that it is a potentially useful predictor of postoperative complications. The at-rest $\mathrm{D}_{\mathrm{LCO}}$ is sensitive enough to detect emphysema, but not sensitive enough to detect mild emphysema. ${ }^{23}$ Thus, in the face of mild disease with slight reduction in alveolar capillary surface, the remaining capillaries, with their ability to distend, might be recruited to replace capillaries involved in the emphysematous lesion, yielding a normal $\mathrm{D}_{\mathrm{LCO}}{ }^{24}$ In those patients, measuring $\mathrm{D}_{\mathrm{LCO}}$ during exercise may detect the abnormally reduced alveolar capillary surface and improve the sensitivity of $\mathrm{D}_{\mathrm{LCO}}$ for detecting emphysema, as suggested by Gelb et al. ${ }^{25}$ In the present study we defined a new useful index, the measured product, obtained by multiplying the preoperative percent-of-predicted $\mathrm{FEV}_{1}$ by the preoperative percent-of-predicted $\mathrm{D}_{\mathrm{LCO}}$ to predict postoperative complications. ${ }^{10,26}$ The measured product has advantages similar to that of the predicted postoperative product, and the measured product was also useful in predicting postoperative complications.

The patients with complications in our study were more likely to have COPD, more pack-years of smoking, and to be older than the patients without complications. In our previous study the clinical variables were found to be good for predicting postoperative complications. ${ }^{9}$ The diffusion heterogeneity index is elevated in smokers, and is correlated with age in smokers and pack-years of smoking. ${ }^{27}$ Smoking causes abnormalities including ground-glass attenuation, micronodules, and diffuse emphysematous changes. ${ }^{28}$ Inflammation and fibrosis in small airways probably account for the elevated diffusion heterogeneity index in smokers. ${ }^{27}$ Increasing breath-hold time improves gas mixing in the lung, which decreases heterogeneity and hence decreases the diffusion heterogeneity index. ${ }^{7}$ Therefore, the diffusion heterogeneity index might be higher due to shorter breath-holding (because of dyspnea) in those who developed complications, but this potential effect was minimized because the target breath-hold time at rest was only 2 seconds. ${ }^{9}$

During exercise the diffusion heterogeneity index increased in patients with complications and decreased in patients without complications. Since $\mathrm{D}_{\mathrm{LCO}}$ is measured at maximal lung volume, both at rest and during exercise, the change in $\mathrm{D}_{\mathrm{LCO}}$ is more likely to be due to a change in perfusion rather than ventilation. If there is general recruitment of pulmonary capillary blood during exercise, then diffusion will become more homogeneous and diffusion heterogeneity index will decrease. ${ }^{29}$ On the other hand, if blood flow increases preferentially to existing perfused units during exercise, then diffusion becomes more concentrated in one region, and hence more heterogeneous, with a consequent increase in diffusion heterogeneity index. Therefore, an increase in diffusion heterogeneity index with exercise may be an indicator that the lung's response to stress will be toward hyperperfusion of lung units with consequent edema and cardiac dysrhythmias. This may explain the performance of the preoperative change in diffusion heterogeneity index in predicting postoperative complications.

\section{Limitations}

We used prophylactic interventions to decrease the risk of perioperative morbidity and mortality, including smoking cessation, breathing training, antibiotics, expectorants, bronchodilators, and weight reduction. Intraoperative management 


\section{Predicted Postoperative Product and Diffusion Heterogeneity Index}

included limited anesthesia and thoracotomy time, intermittent hyperinflation to prevent atelectasis, better control of secretions, prevention of aspiration, and maintenance of bronchodilation. Postoperative measures included incentive spirometry, mobilization of secretions, early ambulation, cough encouragement, and adequate pain control.

\section{Conclusions}

The predicted postoperative variables (predicted postoperative product, measured product, and diffusion heterogeneity index) are potentially useful predictors for preoperative evaluation of candidates for lung resection, but these findings need to be confirmed in larger prospective studies.

\section{ACKNOWLEDGMENTS}

We thank Kenneth Evans MD and Richard Finley MD for help in recruiting patients; Jim Potts $\mathrm{PhD}$ and Sundeep Rai MSc for their advice and help with the 3-equation $\mathrm{D}_{\mathrm{LCO}}$ technique; Sverre Vedal MD for supervising some of the exercise tests and for helpful advice; Hui-Wen $\mathrm{Lin} \mathrm{PhD}$ for his help with the statistical analysis and figures; and Winston Shen MD for editing assistance.

\section{REFERENCES}

1. Wang JS. Relationship of diffusing capacity to postoperative complications. Kaohsiung J Med Sci 2003;19(9):437-446.

2. Santini M, Fiorello A, Vicidomini G, Di Crescenzo VG, Laperuta P. Role of diffusing capacity in predicting complications after lung resection for cancer. Thorac Cardiov Surg 2007;55(6):391-394.

3. Brunelli A, Refai MA, Salati M, Sabbatini A, Morgan-Hughes NJ, Rocco G. Carbon monoxide lung diffusion capacity improves risk stratification in patients without airflow limitation: evidence for systematic measurement before lung resection. Eur J Cardiothorac Surg 2006;29(4):567-570.

4. Ferguson MK, Vigneswaran WT. Diffusing capacity predicts morbidity after lung resection in patients without obstructive lung disease. Ann Thorac Surg 2008;85(4):1158-1165.

5. Markos J, Mullan BP, Hillman DR, Musk AW, Antico VF, Lovegrove FT, et al. Preoperative assessment as a predictor of mortality and morbidity after lung resection. Am Rev Respir Dis 1989;139(4): 902-910.

6. Pierce RJ, Copland JM, Sharpe K, Barter CE. Preoperative risk evaluation for lung cancer resection: predicted postoperative product as a predictor of surgical mortality. Am J Respir Crit Care Med 1994;150(4):947-955.

7. Soparkar GR, Mink JT, Graham BL, Cotton DJ. Measurement of temporal changes in $\mathrm{D}_{\mathrm{LCO}}-3 \mathrm{EQ}$ from small alveolar samples in normal subjects. J Appl Physiol 1994;76(4):1494-1501.

8. Graham BL, Mink JT, Cotton DJ. Implementing the three-equation method of measuring single breath carbon monoxide diffusing capacity. Can Respir J 1996;3(4):247-257.

9. Wang JS, Abboud RT, Evans KG, Finley RJ, Graham BL. Role of exercise diffusing capacity in the preoperative evaluation of patients for lung resection. Am J Respir Crit Care Med 2000;162(4):14351444.

10. Wang JS. Relationship of predicted postoperative product to postpneumonectomy cardiopulmonary complications. J Chin Med Assoc 2003;66(11):643-654.
11. Nakahara K, Monden Y, Ohno K, Miyoshi S, Maeda H, Kawashima $\mathrm{Y}$. A method for predicting postoperative lung function and its relation to postoperative complications in patients with lung cancer. Ann Thorac Surg 1985;39(3):260-265.

12. Nakahara K, Ohno K, Hashimoto J, Miyoshi S, Maeda H, Matsumura A, et al. Prediction of postoperative respiratory failure in patients undergoing lung resection for lung cancer. Ann Thorac Surg 1988;46(5):549-552.

13. Daniel WW. Regression analysis: some additional techniques. In: Daniel WW, editors. Biostatistics: a foundation for analysis in the health sciences. New York: John Wiley \& Sons; 1999:536-552.

14. Mould RF. Sensitivity and specificity. In: Mould RF, editors. Introductory medical statistics. Philadelphia: IOP Publishing; 1998:232238.

15. Schisterman EF, Perkins NJ, Liu A, Bondell H. Optimal cut-point and its corresponding Youden index to discriminate individuals using pooled blood samples. Epidemiology 2005;16(1):73-81.

16. Perkins NJ, Schisterman EF. The inconsistency of "optimal" cut points obtained using 2 criteria based on the receiver operating characteristic curve. Am J Epidemiol 2006;163(7):670-675.

17. Hanley JA, McNeil BJ. A method of comparing the areas under receiver operating characteristic curves derived from the same cases. Radiology 1983;148(3):839-843.

18. Silvestri GA, Spiro SG. Carcinoma of the bronchus 60 years later. Thorax 2006;61(12):1023-1028.

19. Bolliger CT, Guckel C, Engel H, Stohr S, Wyser CP, Schoetzau A, et al. Prediction of functional reserves after lung resection: comparison between quantitative computed tomography, scintigraphy, and anatomy. Respiration 2002;69(6):482-489.

20. Larsen KR, Lund JO, Svendsen UG, Milman N, Petersen BN. Prediction of postoperative cardiopulmonary function using perfusion scintigraphy in patients with bronchogenic carcinoma. Clin Physiol 1997;17(3):257-267.

21. Mitsudomi T, Mizoue T, Yoshimatsu T, Oyama T, Nakanishi R, Okabayashi K, et al. Postoperative complications after pneumonectomy for treatment of lung cancer: multivariate analysis. J Surg Onc 1996;61(3):218-222.

22. Pieretti P, Alifano M, Roche N, Vincenzi M, Forti Parri SN, Zackova $\mathrm{M}$, et al. Predictors of an appropriate admission to an ICU after a major pulmonary resection. Respiration 2006;73(2):157-165.

23. Morrison NJ, Abboud RT, Muller NL, Miller RR, Gibson NN, Nelems B, Evans KG. Pulmonary capillary blood volume in emphysema. Am Rev Respir Dis 1990;141(1):53-61.

24. Spencer H. Emphysema. In: Spencer H, editors. Pathology of the lung. Oxford: Pergamon Press; 1985:588.

25. Gelb AF, Gold WM, Wright RR, Bruch HR, Nadel JA. Physiologic diagnosis of subclinical emphysema. Am Rev Respir Dis 1973; 107(1):50-63.

26. Wang JS. Pulmonary function tests in preoperative pulmonary evaluation. Respir Med 2004;98(7):598-605.

27. Cotton DJ, Mink JT, Graham BL. Nonuniformity of diffusing capacity from small alveolar gas samples is increased in smokers. Can Respir J 1998;5(2):101-108.

28. Remy-Jardin M, Remy J, Boulenguez C, Sobaszek A, Edme JL, Furon D. Morphological effects of cigarette smoking on airways and pulmonary parenchyma in healthy adult volunteers: CT evaluation and correlation with pulmonary function tests. Radiology 1993; 186(1):107-115.

29. Cotton DJ, Graham BL. Single-breath carbon monoxide diffusing capacity or transfer factor. In: Hamid Q, Martin J, Shannon J, editors. physiological basis of respiratory disease. Quebec: BC Decker; 2005: 6596-6569. 